ISIDORIANUM 25/49 (2016) 159-186

\title{
EL TESTAMENTO DE DON FRANCISCO DE SOLÍS FOLCH DE CARDONA, CARDENAL ARZOBISPO DE SEVILLA (1755-1775)
}

\author{
David Chillón Raposo \\ Historiador del Arte - Sevilla
}

\section{RESUMEN / ABSTRACT}

El cardenal don Francisco de Solís Folch de Cardona murió en Roma el 12 de abril de 1775 . Con una dilatada carrera cortesana y eclesiástica vivió una vida holgada, sus excesos económicos, su tren de vida y sus atenciones a los necesitados fueron las características más relevantes de su personalidad como prelado. Al igual que en Roma, Sevilla celebró solemnes exequias en su memoria, y un año más tarde se depositó su corazón en el convento de capuchinas de Santa Rosalía, como era su deseo. Antes de su último viaje a Italia, en 1766 dejó rubricado un documento con sus últimas voluntades, en él dejaba como heredero universal al deán y cabildo de la catedral de Sevilla, y nombrados a todos sus albaceas, provocando entre ellos una serie de conflictos de difícil solución. El artículo concluye con la aportación de un anexo con la transcripción de una copia del testamento del cardenal don Francisco de Solís Folch y Cardona que solicitó su hermano y albacea, don Alonso de Solís Folch de Cardona, IV duque de Montellano.

Cardinal Francisco de Solis Folch de Cardona died in Rome, April 12th, 1775. He lived a long, wealthy life, full of economic excesses, combining his expenses with his attentions to poor people, as main characteristics of his personality as bishop. Both Rome and Seville were scenarios of solemn funerals, and one year later his heart was buried at St. Rosalie's Convent, as he wished. Before his last travel to Italy, in 1766, he wrote a document containing his last wills. In such a document, he declared as heir the council of canors from Seville Cathedral, naming also his 
executor and creating a lot of difficult to solve conflicts between them. This paper ends with an annex translating a copy of the testament from cardinal Francisco de Solis Folch y Cardona, as it was asked by his brother and executor Alonso de Solis Folch de Cardona, Fourth Duke from Montellano.

"Día aciago fue el Miércoles Santo, 12 de abril [de 1775], cuando el cabildo [de la catedral de Sevilla] por cartas de Roma supo la muerte de su amadisimo prelado el Eminentísimo Señor Don Francisco de Solís, Cardenal de la Santa Romana Iglesia con el titulo de los Santos Apóstoles, sucedia en dicha capital el 21 de marzo a las tres y media de un violento dolor de costado".

De esta manera Matute da noticia en sus Anales eclesiásticos de la defunción de este ilustre arzobispo de Sevilla. ${ }^{1}$

Don Francisco de Solís Folch de Cardona nació en Madrid el 16 de febrero de 1713, siendo hijo de don José de Solís y Gante, duque de Montellano, mayordomo y caballerizo mayor del cardenal infante

\footnotetext{
Justino MATUTE Y GAVIRIA, Anales eclesiásticos y seculares de la muy noble y muy leal ciudad de Sevilla... que contienen las más principales memorias desde el año de 1701... hasta el de 1800, vol. II, Sevilla, 1887, 258; José ALONSO MORGADO, Prelados sevillanos ó Episcopologio de la Santa Iglesia Metropolitana Patriarcal de Sevilla con noticias biográficas de los señores obispos auxiliares y otros relacionados con esta Santa Iglesia que escribió por disposición del Emmo. y Rumo. Sr. Cardenal Arzobispo Dr. D. Benito Sanz y Forés, Sevilla: Lib. e Imp. de Izquierdo y Compañía, 1906, 669-672; Archivo de la Catedral de Sevilla (A.C.S.), Fondo Capitular, Sección Primera Secretaría, Autos Capitulares (1775-1776), Sign. 07187, f. 54, cabildo extraordinario celebrado el Miércoles Santo, 12 de abril de 1775, presidiendo el deán y canónigo de la catedral de Sevilla don Miguel Antonio Carrillo: "Concluidos los divinos oficios se llamó al cabildo y se expuso que por cartas de Roma dirigidas al cabildo de los Señores Canónigos, se avisa la fatal noticia de haber fallecido en aquella corte el 21 de marzo de este año el Eminentísimo y Excelentísimo Señor Don Francisco de Solís, Cardenal y Arzobispo de esta Santa Yglesia, que fue arrebatado al violento impulso de un dolor agudo de costado, en solo tres días y medio. Y que estaba señalado por el cabildo de Señores Canónigos el funeral de cuerpo presente: la vigilia en la tarde del día martes 18, y la misa en miércoles 19 de este mes. Y que por no estar aún resuelto por dicho cabildo, el tiempo de las honras no se cuenta. Habiendo oydo el cabildo con dolor de la pérdida de tan gran prelado, esta relación, se mandó entrar al Maestro de Ceremonias, y en la forma acostumbrada, se dixo un responso oficiado por el Señor Deán. Salió el Maestro de Ceremonias y encargaron a los Señores Presbiteros tres misas para cada uno, y a los Señores no Presbiteros tres oficios enteros de defuntos cada uno".
} 
don Luis Jaime de Borbón, y de doña Josefa Folch de Cardona, marquesa de Castelnovo y de Pons. El matrimonio concibió dos hijos más, Alonso, el primogénito y heredero del ducado, y José, que ocupó el cargo de virrey de Nueva Granada entre 1753 y 1762. Don Francisco de Solís Folch de Cardona tomó los hábitos el mismo año que su sobrina doña Josefa, quien fue trasladada al convento del Espíritu Santo de Sevilla en 1767 por mediación del prelado. Su niñez y juventud transcurrió en la corte como compañero de juegos del infante don Carlos, quien por accidente hizo que perdiese el ojo izquierdo. En torno a la formación de Solís existen disparidad de opiniones, ya que unos autores apuntan a que no tendría formación reglada a pesar de que Morgado afirmase que cursó sus estudios en la Universidad de Alcalá de Henares, sin indicar cuales, mientras que los investigadores Ladero y Martín Riego han hallado documentación que confirma que obtuvo el grado de bachiller en cánones por el colegio de San Antonio de Sigüenza. Además, esta información fue corroborada por el clérigo malagueño José Sánchez, que acreditaba la formación del prelado y lo validaba para ocupar cargos de responsabilidad en Madrid y en la Iglesia Universal. Fue por ello que su liberalidad obtuvo diferentes prebendas en la corte de Felipe V, entre ellas el puesto de prioral de Aracena en 1735 y años después el cargo de sumiller de oratorio y cortina del infante don Felipe, posteriormente también lo sería de su esposa doña Luisa Isabel de Francia. Su actuación en la corte fue ejemplar, siendo nombrado canónigo de la catedral de Málaga con la dignidad de tesorero, hasta ser elegido en 1744 deán de la misma. Con 36 años de edad, el 20 de enero de 1749 fue nombrado en Madrid obispo titular de Trajanópolis con dispensa de grado, y al tiempo coadministrador in spiritualibus del arzobispado de Sevilla. Fue consagrado por el cardenal nuncio don Enrique Enríquez en el convento de la Encarnación de Madrid el 16 de marzo de ese mismo año, siendo la noticia acogida con alegría en los colegios dominicos y jesuitas de ambas diócesis. Tras la muerte del obispo don Miguel Vicente Cebrián, el 25 de septiembre de 1752 fue trasladado a Córdoba como obispo electo, realizando la ceremonia de ingreso y juramento el 24 de diciembre ese mismo año. Como prelado de esta diócesis realizó la única visita pastoral que por precepto le obligaba su cargo entre los años 1753 y 1754, iniciándola por la zona de la campiña. El 17 de noviembre de 1755 fue promovido a Sevilla como arzobispo, siendo elevado a la dignidad cardenalicia 
el 5 de abril de 1756 por el papa Benedicto XIV, quién le otorgó el palio y el título de los Doce Apóstoles. Además, recibió en la ciudad diferentes honores, entre ellos el cordón de San Genaro o el hábito de la Real Orden de Carlos III en 1771. Desde sus inicios en el gobierno de la archidiócesis hispalense tuvo el apoyo de un obispo auxiliar, estando ya nombrado para tal efecto antes de su llegada don Domingo Pérez de Ribera y Alvarado (1741-1771) y a su muerte don Agustín de Ayesterán y Landa (1772-1796). ${ }^{2}$ Como arzobispo de Sevilla obtuvo de la universidad diversos doctorados honoríficos por los servicios prestados a la institución, a la ciudad y a la corona, citando como ejemplo el de teología, recibido en 1772 por su decisiva actuación en el traslado de la universidad desde el antiguo colegio de Santa María de Jesús a la antigua casa profesa de los jesuitas. ${ }^{3}$

Como prelado hispalense quiso Solís mejorar la disciplina eclesiástica dictando en 1757 un mandato dirigido a todos los sacerdotes de la diócesis. En él exigía la asistencia a los rezos en comunidad y a las conferencias morales, así como el uso de una indumentaria eclesiástica adecuada y el obligado cumplimiento de todo lo establecido en los sínodos diocesanos. Diez años después reiteró cada una de las ordenanzas de este texto en otro, en el que insistía en el ejercicio de una mayor disciplina sobre la población religiosa que gobernaba, recomendando también la práctica individual y colectiva de una mayor honestidad en la práctica de las costumbres eclesiásticas. Por este último motivo encargó al padre don Pedro Calatayud una misión general dirigida a las diferentes parroquias del arzobispado y que abordaría la comunidad jesuítica, ya que en ese momento gozaba del favor del cardenal. Como arzobispo de Sevilla realizó, al igual que en

2 Manuel MARTÍN RIEGO, Sevilla de Las Luces, en Carlos ROS, "Historia de la Iglesia de Sevilla", Sevilla 1 (1992)525-526 y 531-532.

3 Carlos L.LADERO FERNÁNDEZ y Manuel MARTÍN RIEGO, Arzobispos y caridad en la Iglesia de Sevilla (1755-1799), en "Anuario de Historia de la Iglesia Andaluza" 7 (2004) 43-98. Es especialmente interesante este amplio artículo de madurez de Martín Riego porque reflexiona y revisa alguno de sus textos anteriores, amplía y aporta nuevos datos, así como actualiza otros que la propia actividad investigadora ha incorporado; Véase Manuel MARTÍN RIEGO, Diezmos eclesiásticos, rentas y gastos de la mesa arzobispal hispalense (1750-17800), Sevilla, 1990. 
Córdoba, la obligada visita pastoral a la diócesis, destacando su incidencia en las localidades de Lebrija y La Campana. En dos ocasiones viajó a Roma para participar en la elección de los pontífices Clemente XIV y Pío VI, en los cónclaves celebrados en años 1769 y 1775 , respectivamente. ${ }^{4}$

Don Francisco de Solís Folch de Cardona fue un hombre presuntuoso y malgastador que tuvo a su servicio un gran séquito formado por setenta y cinco criados, ascendiendo sus salarios a 176.020 reales anuales. Mayor generosidad planteó en el reparto de sus dádivas, ya que según afirmó Domínguez Ortiz "mantuvo hasta el fin de sus días un magnífico tren de vida y una bolsa siempre abierta a los necesitados". Entre las comunidades que estuvieron bajo su cuidado tuvo especial atención a los conventos femeninos frente a otros, resultando más favorecidas las congregaciones de las Mínimas de Triana, las Capuchinas, el convento del Socorro o el Beaterio de Agustinas. Además, los gastos realizados por Solís en la promoción de parroquias y conventos en la archidiócesis de Sevilla ascendieron a más de cuatro millones de reales, invertidos en las iglesias de las localidades de Villaverde, Brenes, Cantillana y Umbrete, donde acometió en esta última las obras restauración y ampliación de su palacio de verano y un hospital de nueva planta. En la capital reedificó la iglesia del convento de Santa Rosalía, el colegio de la Becas y la iglesia parroquial de San Roque, entre otras obras. Tal fue su dispendio que se vio obligado a solicitar al rey una prórroga en 1764 para poder asumir sus gastos, ya que además de las deudas contraídas con la corona estaba empeñado con varios particulares por un cómputo de 120.000 pesos. Debido a su constante derroche económico, diez años después solicitó al cabildo de la catedral un préstamo, que fue concedido, de 60.000 pesos para poder emprender su último viaje a Roma, como así lo atestiguan los Autos Capitules de ese año. La presencia del prelado en la corte papal fue recordada en la Iglesia de Sevilla por los elevados gastos en las funciones religiosas, fiestas y limosnas, citando como ejemplos los 89.113 escudos y 86 bayocos empleados para la celebración del conclave de 1769, el precio del alquiler de su palacio en la Piazza Colonna y las grandes sumas de dinero

4 Manuel MARTÍN RIEGO, Sevilla de las Luces, 525. 
empleadas en fiestas y recepciones. Grandes fueron también los dispendios que tuvo con motivo de la toma de posesión del título de cardenal presbítero de la basílica de los Doce Apóstoles en Roma de la que era su titular. ${ }^{5}$

Tras finalizar el cónclave para la elección del papa Pío VI en diciembre de 1774, el cardenal Solís cayó enfermo en su palacio romano causado por los rigores del invierno. Ladero narra cómo el viernes 17 de marzo de 1775 "fue sorprendido por un fuerte frío que le duró largo tiempo, siguiose a éste su correspondiente calentura con dolores molestos por el cuerpo y alguna fatiga al pecho". Debido a esta recaída falleció tres dias después a los 62 años de edad, víctima de una pulmonía y aquejado de fuertes dolores en el costado, en plenas facultades mentales y cuando se disponia a regresar con su segunda esposa, la Iglesia de Sevilla. En sus últimos momentos estuvo acompañado por los doctores Buendia y Salicete, y de su confesor, el fraile mínimo don Jaime Serrano, quién "lo consoló, rezó un credo con él y le dio la última absolución", solicitando en su lecho de muerte el sacramento de la eucaristía y la extremaunción. Para las honras del cardenal Solís en Roma su cuerpo fue trasladado a la Basílica de los Doce Apóstoles para ser embalsamado, y alli se construyó un túmulo funerario cubierto con un gran dosel de pesado paño con un capelo en la zona inferior que acogía el cuerpo del difunto. Su cuerpo fue introducido en una caja de madera y a su vez en otra de plomo, por ellas la familia pagó 110 escudos a Esteban Raymundi y a José Alesio. Esta arquitectura efímera se rodeó de antorchas y cuatro grandes banderolas flanqueando cada una de las esquinas de la estructura. El fasto religioso fue tal que la misa estuvo presidida por el nuevo papa Pío VI, oficiada por el cardenal camarlengo Calini y concelebrada por más de treinta cardenales. Además, la familia encargó cuatrocientas treinta y tres misas al sacristán de la basílica, gastándose un total de 86,60 escudos. ${ }^{6}$ Vázquez Soto da noticia como su corazón fue extraído de

Id., 526.

6 Carlos L. LADERO FERNÁNDEZ, La buena muerte de los arzobispos de Sevilla en el Setecientos, en "Tiempos Modernos: Revista electrónica de Historia Moderna" 30 (2015) 1-27; véase Jaime GARCÍA BERNAL, El ritual funerario de los arzobispos de Sevilla según los cuadernos manuscritos de los maestros de ceremonias de la catedral hispalense (siglos XVII-XVIII), en “e-Spania, Revista Electrónica” 17 (2014). 
su cuerpo en Roma e introducido "en un pomo de cristal depositado en una arquita que se envió a Sevilla para ser colocado en una hornacina en el convento de las Capuchinas, próximo a la reja de la iglesia, en el interior del coro". ${ }^{7}$

La triste noticia llegó a Sevilla el 12 de abril de 1775, por lo que el cabildo de la catedral hispalense, "a quien había instituido su heredero del residuo de su haber con el objeto de culto divino", celebró las exequias los días 18 y 19 de abril, asistiendo a tan solemne acto todo el clero y comunidades religiosas de la diócesis. En esta ocasión se invitó también al colegio de carmelitas calzados de San Alberto, por cercanía de esta institución al cardenal Solís. Como era costumbre, se siguió el ceremonial dictado en los manuales conservados en la catedral, celebrando el rito religioso como si estuviese presente el cuerpo del prelado. Por ello, los capitulares siguieron el ejemplar de otras honras anteriores celebradas en 1631 por otro arzobispo sevillano fallecido en Ancona (Italia), don Diego Guzmán de Haro. El sermón estuvo a cargo del prior del real convento de San Pablo fray Nicolás Cobano, "y se repitieron las lágrimas renovando la memoria de su generosidad y caridad con los pobres, por las que varias ocasiones se vio empeñado." ${ }^{8}$ La citada misa y la vigilia se oficiaron con otros actos una vez acabada la Semana Santa, licencia que se pudo permitir el cabildo al fallecer el cardenal fuera de la ciudad. En primer lugar, el deán de la catedral, don Miguel Carrillo, declaró la Iglesia de Sevilla en sede vacante y mandó el toque de las campanas de la Giralda, siendo cuarenta toques de la mayor por espacio de dos horas y doble continuo durante veinticuatro, interrumpiéndose por el Gloria de los oficios del Jueves Santo hasta la Pascua de Resurrección. En el ínterin el cabildo aprovechó para acondicionar la catedral, cubriendo el altar mayor con un frontal negro y quitar la tarima de la silla de coro del prelado, entre otras acciones. Además, se levantó en el entrecoroun catafalco cubierto de terciopelo carmesí rodeado de candeleros con cera blanca, bajo el cual se depositó una caja vacía

7 José María VÁZQUEZ SOTO, Don Francisco de Solís Folch de Cardona, el noveno cardenal del titulo de los Doce Apóstoles, en "ABC Sevilla" 1 (4/01/1984)63. E1 autor cita como la fecha de defunción el 22 de marzo de 1775, sin embargo, en los Autos Capitulares de ese año aparece un día antes.

8 MATUTE Y GAVIRIA, Anales eclesiásticos, 259. 
sobre una alfombra emulando la presencia del cuerpo muerto del arzobispo. Al morir el cardenal fuera de Sevilla este espacio catedralicio cobró mayor relevancia ya que el ritual sagrado giraba en torno a la ausencia del difunto. ${ }^{9}$

El corazón de don Francisco de Solís y Cardona regresó a Sevilla el 22 de octubre de 1776, siendo depositado en una hornacina del coro bajo del monasterio de las capuchinas de Santa Rosalía por un familiar del cardenal, don Juan Ponce. A este solemne acto acudieron diferentes familias nobiliarias de la ciudad por invitación de la propia abadesa, y se le encargó al escultor italiano Juan Adán un busto con la imagen del arzobispo realizado en fino alabastro con un vástago del mismo material, que además de fijarlo a su base unía simbólicamente la escultura a la pequeña urna funeraria. La efigie

9 Carlos L.LADERO FERNÁNDEZ, La buena muerte de los arzobispos de Sevilla, 1-27. "Los mayores desembolsos que se hicieron en las exequias del cardenal Solís fueron en cera, más de 20.000 reales. Para la vigilia y misa de cuerpo presente del arzobispo Solís en abril de 1775 se distribuyeron cerca de cien arrobas de cera amarilla y blanca a costa del expolio, veintiocho a las comunidades, veintiséis al clero parroquial, quince arrobas y ocho libras para surtir el aparato del altar mayor, once a los ministros del coro, doce a los capitulares y dos arrobas con tres libras y media para el túmulo instalado en el entrecoro. Según una certificación del libro de fábrica, solamente se gastaron 88 arrobas y una libra. La iglesia del sagrario recibió 1.425 reales en concepto de derechos parroquiales por las exequias de Solís, cantidad minima por haber fallecido en el exterior, y la tradicional ofrenda en especie al cabildo se tradujo en 1.400 reales. En general podria decirse que los funerales de un arzobispo hispalense en el siglo XVII podrian superar los 50.000 reales de media. Morir fuera de Sevilla hace pensar que podría haber una disminución de capital. Sin embargo, la documentación de la Embajada de España revela que a los 25.393, 32 reales que le costó al expolio de la catedral los funerales de Solís hay que incrementarle las exequias romanas, dando valores por encima a los 65.000 reales. En la cuenta elaborada por el notario Felipe Mariotti se incluyen un encargo de misas, la asistencia del médico Saliceti y del cirujano Praseti en la enfermedad y abertura del cadáver, los derechos de los curas de las basílicas de los Doce Apóstoles y de Sant'Andrea delle Fratte, las limosnas a los monaguillos, la gratificación del colegio de cardenales, los horarios del maestro carpintero, albañil y hojalatero, la factura extendida por el boticario o las banderolas y armas que decoraron el templo así como los materiales para su reforma. De todos estos conceptos, el mayor desembolso fue ocasionado por el altarero Agustín Giorgi que cobró 250 escudos por la tela, pintura y mano de obra tras formar dos capiteles en el altar mayor de la iglesia de los Santos Doce Apóstoles. También fueron importantes los gastos en cera, importando un total de 2.099 escudos romanos con 24 bayocos y medio, más de 40.000 reales". 
serviría de testimonio del cariño y patronazgo que ejerció el cardenal Solís y su familia sobre la institución conventual, como así también lo atestigua la colección de retratos pictóricos que se conserva en el monasterio, entre los que se encuentra otra imagen del prelado en la sacristía que había estado con anterioridad en el colegio de Becas y tras la extinción de la Compañia de Jesús lo mandó colocar en el monasterio entre otros dos, el de su tío don Jaime de Palafox y Cardona (1684-1701) y el de don Luis de Salcedo y Azcona (1722- 1741), antecesores en la mitra sevillana. Estos retratos están atribuidos al pintor sevillano Domingo Martínez. ${ }^{10}$ Forman parte de esta serie otros retratos de benefactores de la institución, citando como ejemplos el de la abadesa fundadora y tía del cardenal Solís doña Josefa Manuela de Palafox y Cardona, el de su prima sor Andrea Serafina Moncayo y Palafox o el de don Valentín Lampérez, deán y albacea testamentario de don Jaime de Palafox y Cardona. ${ }^{11}$

El 16 de noviembre de ese mismo año se volvió a evocar el recuerdo del cardenal en otro acto solemne en el mismo convento,

10 Alfredo J. MORALES MARTÍNEZ y Enrique VALDIVIESO GONZÁLEZ, Sevilla oculta: monasterios y conventos de clausura, Sevilla, 1987, 273-292. En 1071 llegaron de Zaragoza a la sede hispalense una comunidad de cinco monjas capuchinas, estando al frente de ella doña Josefa Manuela de Palafox y Cardona, hermana del arzobispo de Sevilla don Jaime y devoto de la advocación panormitana. A este ilustre personaje se debe la fundación de este convento. Murió cuando solo se había cimentado el edificio, dejando en su testamento el cuidado de la institución a don Valentín Lampérez, quien junto a la abadesa fueron los responsables de continuar la obra gracias a las limosnas y donativos reunidos. Tras la muerte de sor Josefa Manuela fue fundamental la actuación del arzobispo don Luis de Salcedo y Azcona, quien puso especial empeño en que se concluyera la obra. El 13 de agosto de 1761 se produjo en la iglesia un incendio que se extendió por todo el monasterio, y fue el cardenal Solís quien tomó a su cargo la responsabilidad de su reconstrucción, reuniendo capital de la corona, de particulares y de los suyos propios. Las obras se concluyeron con toda celeridad, con mucho mas esplendor a lo que estaban acostumbradas las comunidades capuchinas, justificando el exceso por ser "un templo consagrado a Dios por un principe de la Iglesia y no podía ser menos que suntuoso". Llama especialmente la atención el conjunto de arquitecturas lignarias de la iglesia, del artista Cayetano de Acosta, y las dádivas del cardenal Solís al convento, destacándose, entre otras, una vitrina rococó, que también pudiera ser de Acosta, con una imagen de un crucificado en porcelana, y el relicario del lignum-crucis.

11 Véase David CHILLÓN RAPOSO, Patrocinio y mecenazgo del arzobispo don Jaime de Palafox y Cardona, Universidad de Sevilla, Sevilla, 2016 (Tesis Doctoral inédita); Jesús PORRES BENAVIDES, Un original desconocido (o perdido) y tres versiones del retrato del cardenal Solís, en "Archivo Español de Arte", vol. 81, 323 (2008) 315-322. 
esta vez organizado por el cabildo de la catedral hispalense y presidido por don Manuel de Castro. A él asistieron el nuevo arzobispo don Francisco Javier Delgado y Venegas y la Universidad de Beneficiados, entre otros, estando a cargo del sermón el racionero y antiguo secretario del prelado don Antonio Salinas, y acompañando al acto la música de capilla de la catedral. Ese día se colocó una pequeña lápida debajo del busto con la siguiente inscripción: "El corazón del Eminentísimo Cardenal Arzobispo de Sevilla Francisco de Solís, descansa conservado en este lugar, entre sus amadísimas hijas, para que, asi como cuando vivo las acompañaba con tierno afecto, así ahora difunto mantengan esta prenda de su amor". ${ }^{12}$

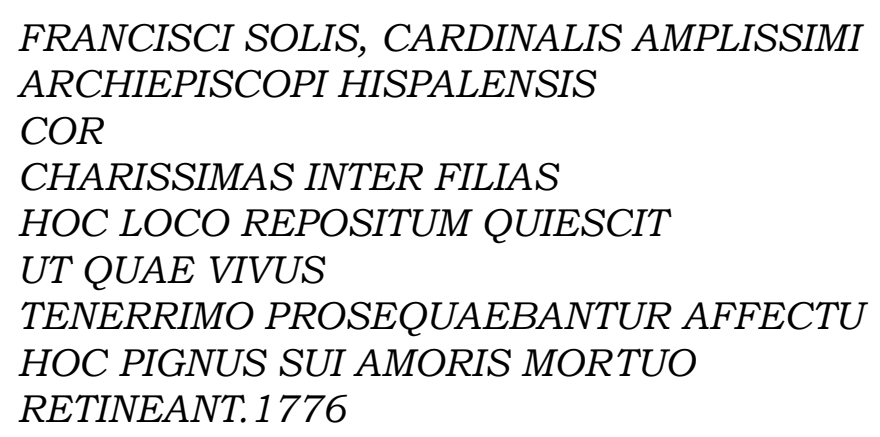

Como se ha dicho, el 12 de abril de 1775 el deán y canónigo de la catedral de Sevilla don Miguel Antonio Carrillo mandó al secretario leer en un cabildo extraordinario una carta que había llegado de Roma, en ella se informaba a los capitulares del fallecimiento del cardenal Solís en aquella corte. Junto a este documento lo acompañaba otro con las últimas voluntades que había dejado ordenadas el difunto arzobispo. ${ }^{13} \mathrm{El}$ deán pidió al secretario que mandase pasar a un notario que esperaba la venia de entrada a la sala capitular y que era la persona elegida "para dar razón de la disposición última, que se dice haber hecho el señor prelado difunto". Una vez dentro dio lectura al testamento, fechado en Sevilla el 18 de octubre de 1766 ante el escribano público don

ALONSO MORGADO, Prelados sevillanos, 670-671.

13 Archivo de Protocolos Notariales de Sevilla (A.H.P.N.S), Sección Protocolos Notariales, of. 19, leg. 13.149, Testamento del cardenal don Francisco de Solís Folch de Cardona, f. 1606, doc. cit. en Carlos L. LADERO FERNÁNDEZ, La buena muerte de los arzobispos de Sevilla, 19. 
Pedro Leal, e "hizo constar que el cabildo era instituido heredero del residuo del haver de dicho Señor Eminentísimo", expresando su deseo de que todo aquello que quedase en posesión de los capitulares fuese destinado al culto divino. El cabildo, como era costumbre, admitió la herencia del cardenal y encargó al canónigo y mayordomo de fábrica don Pedro del Campo la realización de un inventario "para que en su representación asista a el que se haga de este residuo, y distribución de él". ${ }^{14}$

El 26 de ese mismo mes Campo informó que se había dirigido en repetidas ocasiones al arcediano de Niebla don Ignacio Ceballos como subcolector de expolios del arzobispado, solicitándole un informe detallado de las pertenencias del cardenal Solís en sus oratorios y una relación de todos los pontificales que tenía en su haber hasta el día de su muerte. El canónigo se quejaba ante los capitulares de la resistencia de éste a entregarle dicha información, "dando por respuesta a sus instancias que carecía de orden para entregar". Por diputación, el deán ordenó al tesorero don Pedro Martín de Céspedes y al licenciado don Francisco de Larumbe, que junto a los mayordomos de fábrica y con exclusión de don Ignacio Ceballos "examinen el derecho de la fábrica a todos los Oratorios y Pontificales de dicho Señor defunto, y los medios que se deban tomar para su recobro, y hagan relación". El 12 de mayo el arcediano de Niebla envió al cabildo dos cartas dirigidas a los capitulares. En la primera pedía que se mandase al contador mayor del arzobispado una relación de todas las posesiones del difunto cardenal hasta el día de su fallecimiento, "y de lo que toca de frutos, y demás efectos en la vacante deste dicho día al Rey nuestro señor"; en la segunda, solicitaba una certificación sobre el estado del préstamo de los 600 pesos que el cabildo había cedido a Solís para realizar su viaje a Roma, "de lo cobrado a quenta del tercio del año próximo pasado cedido por dicho señor para su pago". Por la solicitud real todo hace suponer que los canónigos suministraron inmediatamente la información a Ceballos para no incurrir en un desacato mayor hacia el monarca. Sin embargo, el

14 A.C.S., Autos Capitulares (16775-16776), op. cit., f. 54, cabildo extraordinario celebrado el Miércoles Santo, 12 de abril de 1775, presidiendo el deán y canónigo de la catedral de Sevilla don Miguel Antonio Carrillo. 
cabildo no cejó en mostrar hostilidad hacia el arcediano de Niebla, dificultando cualquier trámite para la resolución del conflicto. Como consecuencia, el 30 de agosto la diputación de negocios informaba que Ceballos reiteraba su negativa de proporcionar cualquier dato al cabildo debido a la falta de una orden expresa del comisario general de cruzada. Ceballos como subcolector del arzobispado no quiso repartir con el cabildo cualquier fondo económico resultado de la venta del residuo de Solís, ya que los gastos que tuvo el cardenal en vida superaban los beneficios que se pudiesen sacar de sus expolios. De esta manera, el arcediano de Niebla no solo protegía los intereses del arzobispado de Sevilla, sino que también defendía los de la corona frente al cabildo. Es paradójico pensar en la hostilidad que sintió Ceballos hacia el cabildo del que formaba parte como dignidad, y significativo también el respeto que sintió hacia el cardenal difunto. Sobre estos rasgos de la personalidad del arcediano de Niebla citar dos ejemplos, ya que siendo un hombre austero y responsable de la administración de la herencia del arzobispo no dudó en hacerse cargo generosamente de los costes de fábrica que se gastaron en la obra de la hornacina en el convento de Santa Rosalía y de la colocación del busto de alabastro en el citado el coro bajo, estando los pagos a cargo del expolio del cardenal; sin embargo Ceballos se enfrentó enérgicamente al mayordomo del comunal por pretender reducir los altos costes de la cera en las exequias de Solís en la catedral de Sevilla, debido a que su importe también debía salir del expolio del cardenal que él administraba. Así, distribuyó finalmente los cirios de mayor calibre únicamente a los capitulares, dejando al resto del clero con velas de media libra, y para controlar el derroche dejo fuera del reparto a los canónigos ausentes o enfermos, así como tampoco accedió a conceder el sobrante al altar mayor o al servicio de los sacristanes y porteros, como era costumbre. ${ }^{15}$

15 Id., fs. 56, 66v-67r y 112 , en cabildos celebrados 26 de abril, 12 de mayo y 30 de agosto de 1775. En este último cabildo "La diputación de negocios en virtud de la comisión de 26 de abril de 1775, con los Señores de Fábrica, Thesorero, y Francisco Larumbe canónigo, cerca del pontifical y oratorio de su eminencia Señor Cardenal de Solís, Arzobispo desta ciudad, y Santa Yglesia, defunto, habiendo precedido llamamiento, informaron por su libro ser necesario hacer representación del derecho de fábrica por mano del señor doctoral diputado en la corte al señor comisario general de cruzada"; Carlos L. LADERO FERNÁNDEZ, 
En referencia a la administración del residuo del cardenal Solís no dejó de plantear serios problemas hasta muchos años después de su fallecimiento. El 14 de agosto de 1786 se celebró un cabildo ordinario presidido por el chantre don Lorenzo Río Estrada y el arcediano de Jerez don Lorenzo Melgarejo. En él se dio lectura a un memorial presentado por la madre abadesa del convento agustino del Dulce Nombre de Jesús, beaterio femenino de Sevilla favorecido en vida del prelado, en el que solicitaba a la fábrica de la catedral "los desechos de esta Santa Yglesia para el servicio y decencia de la suya". La propuesta originó inmediatamente una disputa entre los capitulares porque consideraron que si se efectuase la concesión a la abadesa sería un agravio para las comunidades religiosas el socorrer a ésta frente a las otras. La propuesta se desestimó por no haber consenso entre los canónigos. Aun así, don Ignacio Valencia hizo relación "de todo lo inservible que hubiese de oro, plata, piedras y ropas, a fin de que se pudiese determinar el destino y beneficio de ello". El cabildo pidió a los diputados de fábrica que de ese inventario realizado separasen todos los bienes que hubiesen pertenecido al expolio del cardenal Solís, ya que la Iglesia de Córdoba, su primera esposa mística, los estaba reclamando "y tenía algún derecho a ello". ${ }^{16}$

En paralelo al conflicto de la gestión del expolio, se inició inmediatamente otro con el hermano del difunto prelado, don Alonso de Solís Folch de Cardona, IV duque de Montellano, que junto al deán de la catedral, al arcediano de Jérez y familiar suyo don Alonso Melgarejo, al vicario general del arzobispado y al secretario de cámara fueron todos ellos nombrados albaceas

La buena muerte de los arzobispos de Sevilla, 7: "Todas aquellas rentas y bienes generados por la dignidad eclesiástica serian recolectados, administrados y distribuidos por la Corona, según el Concordato de 1753, a excepción de libros, pontificales, prendas y ornamentos sagrados destinados a la fábrica de la catedral en virtud del matrimonio místico contraído con el prelado. De esta manera la administración borbónica obtenía grandes beneficios. A este concordato le suceden leyes y enmiendas para corregir esta situación tan beneficiosa para la Corona. Una real célula de 17 de febrero de 1771 aprobaba un reglamento donde se alude a las reservas de muebles y adornos para los futuros prelados, además de alhajas de oro y plata".

16 A.C.S., Fondo Capitular, Sección Primera Secretaria, Autos Capitulares (1786), Libro 149, Sign. 07197, fs. 110v-11r. 
testamentarios del cardenal Solís, para "que por derecho en tal caso se requieran para recaudar pedir, recebir y cobrar todos nuestros bienes, ya laxas, rentas, caudal, y efectos patrimoniales, libres, y peculiares, que nos toquen y pertenezcan de cualquier clase que sean, venderlos en almoneda pública, o fuera de ella, y de su procedido satisfacer el funeral del entierro, y misas, deudas, que tuviere pendientes". El duque de Montellano quiso ejercer su derecho como albacea, iniciando un proceso legal muy farragoso contra el cabildo en el que tuvo que intervenir el rey para proteger los intereses de la corona. Por ello, solicitó una copia del testamento porque había observado irregularidades en su tratamiento y entendía vulneradas algunas de las últimas voluntades. Tras una larga espera no exenta de litigios, el documento fue obtenido diez años después por su hijo y sobrino del cardenal, don Álvaro de Solís Wignacourt y Folch de Cardona, V duque de Montellano, ya que don Alonso había muerto el 3 de agosto de 1780, seis años antes de que el cabildo cediese ante la demanda del noble, siendo su heredero quien recogió el texto. ${ }^{17} \mathrm{El}$ testamento fue rubricado por el escribano real don Luis León Pérez y por tres escribanos públicos más de Sevilla, don Antonio Madariaga, don Luis de Palacios y don Antonio Domínguez, estando fechado en Sevilla el 16 de agosto de 1786. Destacar de este documento el carácter regio del funcionario que certificó este segundo escrito, ya que era uso que firmase un escribano público, como era costumbre en estos casos. ${ }^{18}$

E1 24 de mayo de 1775, se leyó en un cabildo extraordinario una carta del duque de Montellano, fechada el 12 de ese mismo mes. En ella comunicaba su deseo de ejercer el derecho que tenía como albacea testamentario de su hermano. Habiendo sido también nombrados responsables para tal efecto el deán y el vicario general, entre otros, resultaba extraño que quisiera intervenir don Alonso de Solís en la administración de los bienes,

17 José Antonio ÁLVAREZ Y BAENA, Hijos de Madrid, ilustres en santidad, dignidades, armas, ciencia y artes. Diccionario histórico por orden alfabético de sus nombres, que consagra el Illmo. y nobilisimo ayuntamiento de la imperial y coronada villa de Madrid, Madrid, B. Cano, 1789-1791, 67-69.

18 Archivo Histórico Nacional (A.H.N.), Sección Nobleza, Fondo Archivo de los Duques de Fernán Núñez, Signatura ES.45168.SNAHN/3, Leg. 915/1, Copia del testamento del cardenal don Francisco de Solís Folch de Cardona, doc. sin foliar. 
ya que la heredera legítima de su hermano era su segunda esposa mística, la Iglesia de Sevilla, y en su nombre el cabildo. ${ }^{19}$ El deán dio comisión plena a la misma diputación de negocios para que estudiase el caso conjuntamente con el anterior, pidiendo a los mismos canónigos Martín de Céspedes, Larumbe y a los mayordomos de fábrica que atendiesen esta inusual petición, con la exclusión nuevamente de esta comisión del arcediano de Niebla, que además de subcolector del arzobispado era juez de expolios. El cabildo se vio presionado a admitir el albaceazgo del hermano del cardenal el 9 de junio, ya que no pudieron obviar legalmente las últimas voluntades y deseos de Solís expresados en su testamento. Para que tuviese efecto esta cesión, el cabildo convino que "se prevenga a dicho Señor Excelentísimo, con la atención maior, que debe formalizarla con otro documento authentico legal". Al mes siguiente contestó el duque de Montellano al cabildo con otra carta en la que incorporaba el testimonio de sustitución de albaceazgo que la diputación de negocios demandó al aristócrata para poder ejercer sus derechos. Este nuevo documento trasladaba al duque las capacidades de libre acción sobre los bienes materiales del cardenal, como si estuviese vivo o enfermo. A pesar de la legalidad de la documentación aportada, el cabildo seguía desconfiando del noble ya que atentaba contra los intereses económicos del eclesiástico, pidiendo al canónigo don Pedro del Campo que examinase exhaustivamente y verificase el testimonio escrito, "para que use de ella como de la que se ha hecho en razón de herencia de dicho Señor Eminentísimo". ${ }^{20}$

El testamento del cardenal don Francisco de Solís Folch de Cardona es un reflejo de lo que fue en la vida y lo que de ella obtuvo, una imagen de sus prioridades y sus preocupaciones. El documento fue firmado por el prelado con plenas capacidades físicas e intelectuales en su palacio arzobispal de Sevilla, con fecha de 18 de octubre de 1766, ante don Pedro Leal, escribano público de la ciudad, y teniendo como testigos a don Francisco

19 A.C.S., Autos Capitulares (1775-1776), op. cit., f. 73v, cabildo extraordinario celebrado el miércoles 24 de abril de 1775 .

20 Id., fs. 80 y 91 , en cabildos celebrados los dias 9 de junio y 7 de julio de 1775 , presidiendo el primero de los cabildos el arcediano de Sevilla don Luis de Madariaga y Bucarelli, y el segundo el arcediano de Niebla don Ignacio Ceballos. 
Saceda del Castillo, canónigo de la iglesia colegial del Salvador, don Félix López de Argul, presbítero y mayordomo de hacienda del prelado, y don Pío García Tagle, presbitero y director de la mesa arzobispal. El anexo que se presenta es una transcripción de la copia que se conserva en el Archivo Histórico Nacional, en la Sección Nobleza de Toledo, solicitado al cabildo a petición de don Alonso de Solís Folch de Cardona, IV duque de Montellano, hermano y uno de los albaceas testamentarios del cardenal, y tras su muerte fue recogido por su hijo don Álvaro de Solís Wignacourt y Folch de Cardona, V duque de Montellano, fechado en Sevilla el 16 de agosto de 1786, ante el escribano del rey don Luis León Pérez y teniendo como testigos a tres escribanos públicos, con el fin de dar "fe y crédito en todos Juicios y Tribunales". El documento original está depositado en el Archivo Histórico de Protocolos Notariales de Sevilla. ${ }^{21}$

Daba comienzo el testamento con una legitimización genealógica del cardenal Solís y con una protesta de fe en la que pedía perdón por todos los pecados cometidos. Aseguraba estar en el pleno conocimiento y testando con el tiempo suficiente para que la muerte no le hallase desprevenido. En primer lugar, expresó su deseo de sepultarse en la catedral de Sevilla en el caso que la muerte le sorprendiese en la ciudad, dentro del recinto cerrado por las barandas del crucero, frente al altar mayor y lo más cerca posible al monumento de plata donde se encontraba expuesto el Santísimo Sacramentado, y le encargó además al cabildo sus exequias y un número indeterminado de misas rezadas para rogar por su alma. Apuntaba Solís también en este punto que si su fallecimiento tuviese lugar fuera del arzobispado dispondrian su entierro los albaceas a su arbitrio.

Como era estilo, destinó 20 reales de vellón a cada una de las obras pias en las que el cardenal estaba empeñado, incluyendo en esta relación a la Santa Casa de Jerusalem. Quiso Solís recobrar un inventario con el patrimonio que poseía antes de su llegada

21 A.H.P.N.S., Testamento del cardenal don Francisco de Solis Folch de Cardona (1766), op. cit., doc. sin foliar; A.H.N., Copia del testamento del cardenal don Francisco de Solís Folch de Cardona (1786), op.cit., doc. sin foliar. 
a Córdoba, compuesto por una bajilla de plata, alhajas, piedras preciosas, coches, tiros de mulas, muebles y otros efectos que no se detallan, recibidos de su padre don José de Solís y Gante. Este fondo fue aumentado cuando ocupó la mitra cordobesa con objetos y dinero adquiridos fuera de la renta decimal de la Iglesia, y que junto a la legítima paterna quiso disponer de ello libremente en vida. Al recibir la herencia de su padre, Solís quedaba fuera del testamento de su madre doña Josefa Folch de Cardona, principalmente por las deudas contraídas y que se debian satisfacer de la difunta duquesa. Cuenta el cardenal que desde la muerte de su padre y hasta la fecha de la firma de este documento había consumido de la legitima 120.000 reales de vellón, faltando por recaudar todo el caudal concerniente a los territorios que poseía la familia en las Indias, bienes libres y rentas de los mayorazgos principalmente, que estaba todavia pro indiviso, con el fin de poder realizar la repartición de dichos bienes con su hermano Alonso, habiendo fallecido su hermano José cuatro años antes de la redacción del documento. La proporción sería de un quinto para el duque de Montellano y un tercio para el cardenal del dinero resultante de todo aquel vasto territorio.

El prelado declaró tener una hacienda de campo en Palmete llamada de San Cristóbal, por aquel entonces a las afueras de Sevilla, y que a fecha de firma del testamento estaba todavía hipotecada debido a las muchas deudas contraídas por el prelado. El cabildo de la catedral se hizo responsable de los pagos invirtiendo en ellos la tercera parte de las rentas del arzobispado, por lo que Solís dispuso la cesión a los capitulares del terreno a su muerte y hasta que ésta estuviese totalmente pagada, y en su defecto a sus albaceas. Una vez resueltos los pagos, la hacienda pasaria perpetuamente a ser propiedad de la dignidad arzobispal para su uso y disfrute, sin posibilidad alguna de poder ser vendida o cedida. Los canónigos únicamente administrarian la hacienda durante el periodo de liquidación de la deuda contraída por el prelado, y del líquido resultante, el deán se encargaría de librar anualmente y de por vida una renta de 400 ducados de vellón a su sobrina, doña María Josefa de Solís Folch de Cardona, novicia del convento del Espíritu Santo de la ciudad, con el compromiso del cabildo de cubrir las costas de su entierro y cancelar sus deudas en el momento que le llegase su muerte. 
El cardenal informaba a los capitulares que las rentas y patrimonio personal que poseía importaba más de 70.000 pesos, y que, a pesar de no haberlos obtenido de los diezmos, los había invertido en las obras de construcción de iglesias y conventos de la diócesis, citando además los trabajos que se realizaron en el palacio arzobispal de verano de la localidad de Umbrete. Pidió humildemente a sus sucesores en la mitra que le bonificasen esa cuantía con el fin de saldar sus débitos, planteando que del sobrante se fundase un hospicio que acogiese a dieciocho sacerdotes con una vida irrefutable, doce $u$ ocho en su defecto, a los cuales se les suministraría casa y comida diaria a cambio de asistir a los enfermos del hospital del Amor de Dios y de llevar una vida recta en comunidad. Encargaría también al cabildo la administración del citado hospital, y otorgó a los albaceas los permisos oportunos para la futura fundación y la selección del terreno para erigir el nuevo edificio. Solís, consciente de sus muchos débitos, advirtió a los canónigos que, en caso de no disponer de fondos suficientes para la fundación del edificio, la cantidad recauda se invirtiese en la realización de una nueva sillería de coro para la catedral. Con esta donación el prelado agradaría al cabildo como administrador de sus rentas y atendería por otro lado a la mayor gloria del culto divino. Afirmaba Solís en el documento que, llegada la hora de su muerte, si el cabildo no hubiese satisfecho todas sus deudas y retribuido todo el capital líquido invertido en ellas, le concedió la potestad de acceder directamente, sin reserva alguna, a todos sus bienes, alhajas, plata labrada, piedras preciosas y otros efectos, con el fin de pagar a todos sus acreedores, siendo el propio cabildo el primero de todos sus deudores en cobrar cualquier cuenta que quedase pendiente.

Una vez nombrados sus albaceas testamentarios les dio poder absoluto para que por derecho recaudasen todas las rentas y bienes de su propiedad con el fin de poder satisfacer los gastos de su entierro y de las misas por su alma, e instituyó como heredero universal de sus bienes al deán y cabildo de la catedral de Sevilla "para que lo convierta y distribuya en el mayor adorno, y culto de Nuestro Señor Sacramentado". 
EL TESTAMENTO DE DON FRANCISCO DE SOLÍS FOLCH DE CARDONA, CARDENAL ARZOBISPO DE SEVILLA (1755-1775)

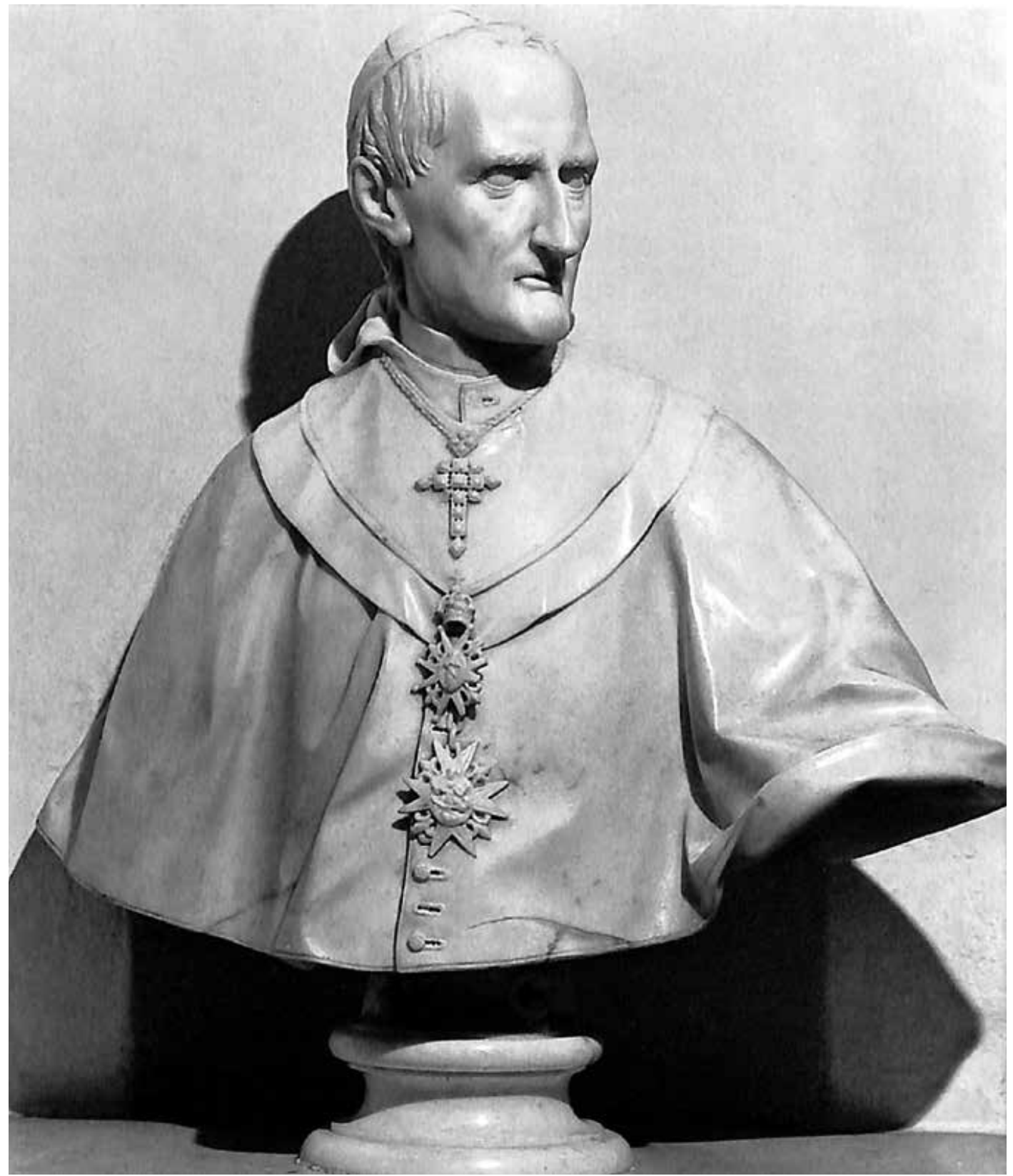

Juan Adán (Roma, 1775). Busto del Cardenal don Francisco de Solís Folch y Cardona. Convento de Santa Rosalia de Sevilla. Coro bajo. 


\section{TRANSCRIPCIÓN DEL TESTAMENTO DE DON FRANCISCO DE SOLÍS FOLCH DE CARDONA (COPIA DE 1786) ${ }^{22}$}

En el nombre de Dios todo/poderoso Amén: Sea notorio a todos los/ que el presente testamento vieren como/ nos Don Francisco de Solís Folch de Car/dona Gante Velbis Rodríguez de las / Barillas, por la Divina providencia/ de la Santa Romana Iglesia Presbí/tero Cardenal, Arzobispo de esta ciu/dad de Sevilla, y su diocessis, Caballero/ de la Real Orden de San Genaro del Con/sejo de su Majestad, hixolegiti/mo del Excelentísimo Señor Don Joseph de/ Solis Gante Sarmiento Rodriguez/ de las Barillas Duque de Monte/llano, y de la Excelentísima Señora Duquesa Doña JosephaFolch de Cardona Vel/ bis de Moncada, y Tribibafanso de/ Romani y Aragón, Marquesa// de Castelnobo, y Pons, señora de las/ varonías de Maralabed, Azuebar,/ Sorneja, Paranchez, Prados y otras,/ mis padres, y señores difuntos, estando/ con salud, y en nuestro libre juicio,/ entendimiento natural cumplida,/ y buena memoria, según la Supre/ma Majestad, fue servido darnos, y creyendo como firme y verdade/ramente creemos, y confessamos/ el ynefable Misterio de la Santíssi/ma Trinidad Padre, Hijo, y Es/píritu Santo tres personas real/ y verdaderamente distintas, y un/ solo Dios verdadero, y todos los/ demás Misterios, que tiene, cree,/ enseña, y manda la Santa Ygle/siaCattholica Apostólica Roma/na, y en esta Fe, protextamos vivir,// y morir como católico, y sí por al/gún accidente, o ympedimento de/ enfermedad, no pudiere a la hora de/ mi muerte hacer (como deseo) es/ta mi confesión, protestación, y pro/fessión de la fee, desde la hora pa/ra entonces, la hago y renueboencomen/dando mi Alma a Dios Nuestro/ Señor, que la crió, y redimió con su/ preciossima sangre, suplicando/ humildemente a su Majestad la/ reciba, ampare, y defienda en aque/ lla última hora dándonos gra/cía, para que recibiendo todos/ los Santos Sacramentos con fee pura, Charidad encendida, y fir $/ \mathrm{me}$ esperanza, nos sean defensa/ para aclarar y lograr el últi//mo fin, para que fuimos criados, ro/gando y suplicando a la Sacratíssi/ma Reyna de los los Ángeles María/ Santísima Nuestra Señora a quien/ en esta vida, siempre hemos tenido/ por abogada intercesora, al Santo/ Ángel de Nuestra Guarda, y cortesa/nos del cielo, que lo sean en la pre/sencia Divina, para que por los/ méritos de la Sagrada

22 Mi más sincero agradecimiento como autor del artículo a la familia Nogales Cardona, que en su interés por buscar sus raices me han facilitado este documento. 
Pasión, y/ Muerte de Nuestro Señor Jesu Chris/to, nos perdonen los pecados, y/ descuidos cometidos en nuestra/ vida, y tiempo de nuestro Minis/terio, alcanzando la salvación/ eterna: Deseando estar preveni/do para quando llegue el lance/ terrible de la muerte, como Ley// inviolable, a que estamos sujetas / todas las criaturas sin saber su/ hora, y que nos coja con disposi/ción y distribución de los bienes, cau/dal y efectos Patrimoniales, y ad/venticios, que habemos adquirido/ fuera de la renta decimal de la/ mitra, y que tenemos facultad/ por la Dignidad Cardenalicia, e/ yndultos, que por ella nos $\mathrm{com} / \mathrm{peta}$, otorgamos que hacemos/ nuestro Testamento, y última/ voluntad en la forma siguiente:

Lo primero, que queremos, y es nues/tra voluntad, que quando la/ Majestad Divina fuere servi/do llevarnos de esta presente vida// siendo en esta ciudad, nuestro cuer/po sea sepultado en nuestra Santa/ Patriarchal Iglesia, dentro de las/ barandas del crucero que va a el/ Altar Mayor, lo más ynmedia/to, que ser pueda, a Nuestro Señor/ Sacramentado, por la expecial/ devoción, que siempre havemos/ tenido a tan soberano Misterio/ permitiendolo nuestro mui ama/do y venerable cabildo de quien/ confiamos, lo tendria a bien, cu/yos funerales se executarán/ según estilo, mandándose decir/ por Nuestra Alma el número/ de missas rezadas, a la limos / na y distribución que está ano/ tado en un papel firmado de// nuestra mano que entregara el su/ geto, en cuyo porder existiese; y si/endo el fallecimiento fuera desta/ ciudad en otra parte, distante/ de nuestro Arzobispado, lo dispon/drán el entierro los Albaceas a/ su arbitrio./

Ytem: Mandamos, a las obras pías/ forsosas que son de estilo, y Casa/ Santa de Jerusalem veinte reales/ de vellón, a cada una de limosna/ por una vez./

Ytem: Declaramos, que quando se/ nos confirió la mitra del obispa/ do de Cordova, hicimos inventa/rio firmado de nuestra mano, de/ la Bagilla de plata, alaxas/ preciosas, coches, tiros de mulas, / / muebles, y demás efectos, con que/ entonces nos hallábamos adquiri/dos de Patrimonio, y alimentos que/ nos estaba dando dicho Excelentísimo Señor/ Duque de Montellanos nuestro Pa/dre: Y después a el tiempo, que entra/mos en la dicha mitra deste Arzobispado,/ hicimos otra memoria de lo augmen/tado con los caudales adventicios/ adquiridos fuera de la renta deci/mal, cuyas dos memorias se ha/llarán en nuestro poder, y su im/porte con la legitima paterna/ que nos toca, es nuestro propio, li/bre, con lo que tenemos suplido a/ la Dignidad Arzobispal, para/ disponer de todo ello como hace/mos en el papel firmado de nuestra// mano, que entregara el sujeto a/ quien lo tenemos confiado./ 
Ytem: Declaramos, que por muerte/ de dicho Excelentísimo Señor Duque de// Montellano nuestro Padre, se ve/rificó no tener yo, que perzevir/ de la lexítima de la Excelentísima Se/ñora Duquesa Doña JosephaFolch/ de Cardona mi Madre mediante/ las deudas, que tenía su Excelencia con/trahídas y fue preciso satisfacer,/ y por lo respectivo a la legitima/ Paterna, solo habemos tomado/ hasta oy, como unos ciento y/ veinte mill reales de vellón, a/ corta diferencia del caudal, que dicho Excelentísimo Señor Duque mi// Padre dejó en España, faltando/ que recaudar todo o que está en/ los Reynos de las Yndias, de los/ bienes libres, y rentas vennidas/ de los Mayorazgos que alli corres/ponden a sus estados, cuyo caudal/ está pro indiviso hasta que se/ vayan haciendo las remesas, en/ que soy ynteresado, por la parte/ que debo haver, como uno de dos / hijos y herederos, que actualmen/te, somos, y que damos partici/pes en dicha herencia con el Excelentísimo/ Señor Duque de MontellanoPri/mogénito nuestro hermano, me/jorado en tercio y quinto, y la/ parte que como tal nos tocare// se ha de poner cobro enteramente/ para el cumplimiento de nuestra disposición./

Ytem: Declaramos tenemos por/ bienes nuestros propios una $\mathrm{Ha} /$ cienda de Campo nombrada de/ San Christóbal, al sitio de Palme/te, pasada la cruz del campo, cu/yo precio se contrató haverlo de/ satisfacer a los planos preveni/dos en la escriptura de venta, y/ respecto a que uno de los debitos/ subsistentes, que tenemos contra/hido es el de la dicha Hacienda con/ todos los demás, en que nos halla/mos empeñados, todos ellos, los ha/ tomado a su cargo irlos pagan/do nuestro mui amado, y vene//rable cabildo de Nuestra Santa $\mathrm{Pa} /$ triarchal Iglesia, por expecial fa/vor que nos ha hecho, cediendo pa/ra enjugarlos, la tercera parte/ de las rentas de nuestro Arzobispado/ con las seguridades y condiciones/ estipuladas, y que ha de contener/ el ynstrumento en su virtud for/malizado, mediante lo qual, y que/dando por este medio libre de la dicha/ Hacienda al tiempo de nuestro/ fallecimiento, si assi sucediere, / y permaneciendo en la mitra/ dispongo, y ordeno, que dicho nues/tro cabildo si gustare (y quan/do no los Albaceas que hemos/ de dexar nombrados) adminis/tren la referida Hacienda, y// perciban y cobren sus frutos en la/ forma, que es estilo, haciendo las/ obras, y beneficios de que necesitare/ y de lo líquido de sus rentas se le den/ a nuestra sobrina Doña María/ Josepha de Solís Folch de Cardona/ Religiosa Novicia en el convento/ del Espíritu Santo de esta ciudad,/ cuatrocientos ducados de vellón/ en cada un año, desde el de nuestro/ fallecimiento en adelante du/rante los días de su vida, para/ subvenir a sus pios usos, y dos / años más de supervivencia, pa/ra que los aplique a su funeral,/ y debitos, si algunos hubiere con/trahído, o disponer de ellos, como/ le pareciere, y cumplido lo susodicho// estando libre en aquel entonces/ de toda responsabilidad de débitos, la dexamos 
en propiedad pose/sión, y usufructo a Nuestra Digni/dad Arzobispal perpetuamente pa/ra siempre gozándola los Señores/ Arzobispos nuestros subcesores, como bienes de su mitra, sin poder/la vender ni enagenar en ma/nera alguna./

Ytem: Declaramos, que las rentas/ y haveres Patrimoniales, que per/ tenecen por peculiar a nuestra/ persona y Dignidad de Arzobispo/ que habemospercebido (separadas/ de todo lo decimal) ascienden a más/ de setenta mill pesos, todos los qua/les los hemos convertido en bene// ficio de la misma Dignidad en las / repetidas obras, que se han ofreci/do de Iglesias, y Conventos de/ nuestra jurisdicción, la quema/ del Palacio de Umbrete, y otras / urgencias, que son notorias, por/ lo que tenemos derecho a dicho cau/dal, y se debe repetir contra la/ vacante por nuestro fallecimiento,/ y Señores Arzobispos subcesores en la/ mitra, a fin de que se nos bonifi/que, y se pague con ello lo que/ quedaremos debiendo, y si sobra/re algo de lo recaudado, el todo o/ parte la cantidad que fuere se/ convierta en la fundación de un/ Hospicio de diez y ocho sacerdotes/ confesores de buena vida, opinión// y fama, que no hayan sido casti/gados por ningún Tribunal, aque/llos que quisieren retirarse, y no/ alcanzando, será de doce, o ocho,/ a los quales se les ha de subminis/trar casa, comida y cena, con/ obligación, que han de tener de/ asistir dos diariamente de dia/ y de noche a confesar, y auxiliar/ los pobres enfermos de nuestro/ Hospital del Amor de Dios des/ta ciudad, y de rezar las horas/ menores en comunidad, todos los/ días, y los clásicos maytines, se/gún y conforme lo tenemos pre/venido en el papel firmado de/ nuestra mano, que entregará/ el sugeto, en cuyo poder parare//y si Nuestro Ylustrísimo Cabildo, quisiere/ tomar a su cargo la administración/ de dicho Hospital, lo dejo a su volun/tad, otorgando sobre ello nuestros/ Albaceas la escriptura de funda/ción con el señalamiento de ren/ta, compreda de fincas en que se/ ha de erigir, clausulas, y condi/ciones precisas a su estabilidad, a/cuyo fin les conferimos absoluta/ facultad sin ninguna limitación, / y previniendo el caso de que no ha/ya fondos para ello, si assísucce/diere, la cantidad, que se recauda/re, se hará con ella, una sillería nueva en el dicho choro de la dicha Nuestra/ Santa Iglesia según determinare/ el cabildo./

Ytem: Declaramos que por quanto// nuestro mui amado, y venerable/ Deán y Cabildo desta Santa Patriar/chal Iglesia, ha usado de la libera/lidad de tomar a su cargo respon/der, y pagar todas mis deudas que/ tengo contraídas a los acrehedo/res, que me afligian por ellas, a/viendo cedido para esto la tercera/ parte de todas las rentas decima/les de nuestro Arzobispado; median/te lo qual en caso de fallecer an/tes, que se haya embolzado ente/ramente de todo lo que fuere pa/gando entregando a los acrehe/dores, y urgencias de nuestra per/sona, con los costos, y gastos, que/ hiciere y se fuere causando, ha/ 
de tener, y le concedemos authori/dad, poder, y absoluta facultad,// para entrar, recoger, percibir, y/ cobrar todos mis bienes y alaxas, / plata labrada, piedras preciosas / y efectos, que nos pertenecieren de/ la mitra sin reservación alguna,/ haciendose pago en primero lugar/ (que otro ningún acrehedor) de/ quanto se hallaren en desembolso,/ como subrogados en sus derechos,/ según las escripturas que lo han/ de comprobar./

Ytem: queremos, y es nuestra volun/tad, que se observe, guarde, y cum/pla enteramente todo lo que cons/tare en el papel, o memoria fir/nada de nuestra mano, que se/ hallara en poder del sugeto que/ la manifestare, si dejaremos cau//dal sobrante para ello, y no ha/ viéndolo reservarán los interesa/dos mi expresión, y afecto, quan/do otra cosa, no haya lugar./

Y para pagar y cumplir lo dispuesto/ y ordenado en las clausulas deste/ nuestro testamento y que se con/tuviese en el citado papel firma/do de nuestra mano, nombramos/ por albaceas al Excelentísimo Señor Don A/lonso de Solís Folch de Cardona/ Gante Velvis Rodríguez de las / Barillas mi hermano Duque/ de Montellano Conde de Zaldue/ ña vecino de la villa y corte de/ Madrid: al Señor Deán, que es o por/ tiempo fuere de nuestra Santa $\mathrm{Pa} /$ triarchalYglesia desde ciudad: a Don// Alonso Melgarejo Arcediano titu/lar Didnidad y Prevendado de la/ misma Santa Yglesia nuestro fa/miliar: a el Provisor y Vicario General: y a el Secretario de Cama/ra, que son o fueren de la Mitra/ y Arzobispado a el tiempo de nuestr/ fallecimiento, a quienes, y a cada uno/ separadamente de por sí ynsolidum/ damos y conferimos poder cumpli/do el más amplio absoluto y bastan/te, con las facultades, que por de/recho en tal caso se requieran/ para recaudar pedir, recebir/ y cobrar todos nuestros bienes, y/ alaxas, rentas, caudal, y efectos/ patrimoniales, libres, y peculia/res, que nos toquen y pertenezcan// de cualquier clase que sean, ven/derlos en almoneda pública, o fue/ra de ella, y de su procedido satis/facer el funeral del entierro, y/ misas, deudas, que tuviere pen/dientes, y cumplir lo demás si/ alcanzare a lo que tenemos dis/puesto en el papel o memoria fir/mada de nuestra mano que pre/sentara el sugeto, a quien lo te/nemos confiado, otorgar cartas/ de pago, finiquitos, gastos, chan/celaciones, poderes cesiones, es/cripturas de fundaciones, adjudi/caciones, compredas, y los demás / instrumentos, que se requieran,/ y para litigar en juicio en los// tribunales superiores, y ordinarios/ eclesiásticos y seglares competen/ tes, hasiendo, y presentando los/ pedimentos autos, y diligencias/ necesarias, usando del dicho cargo/ todo el tiempo que fuere preciso,/ y más sin ninguna limitación,/ sobstituyendo dicho alvaseasgo en/ otras personas, con las mismas/ facultades que dexo conferidas/ en los casos que ocurran./ 
Y después de cumplido, y pagado lo/ que dejamos dispuesto, y ordena/do en las clausulas deste testa/mento, y que se contuviere en el/ papel, o memoria firmado de/ nuestra mano, y satisfechas en/ teramente mis deudas en el// residuo, remanente que quedare/ de todos nuestros bienes libres rai/zesalaxas, dinero,/ débitos, derechos, títulos, acciones, / y otras cosas, que en qualquierma/nera nos toquen y pertenezcan/ al tiempo de nuestro fallecimien/to, y de que tenemos facultad/ para disponer por la Dignidad/ Cardenalicia e Yndultos que por/ ella nos competa, ynstituimos, / y nombramos por nuestro único/ y universal heredero al vene/rable Deán y Cabildo de nues/tra Santa PatriarchalYglesia/ desta ciudad para que lo con/vierta y distribuya en el ma/yor adorno, y culto de Nuestro// Señor Sacramentado, y en los fi/nes destinados en el referido pa/pel, o memoria, citado, por ser/ assí nuestra libre y expontanea/ libertad./

Y revocamos, anulamos, y damos/ por de ningún valor ni efecto to/dos y qualesquier testamentos,/ mandas, codicilos, poderes para/ testar, y otras ultimas disposi/ciones anteriores, que hubieresmos/ hecho, y otorgado por escripto, y/ de palabra, para que ninguno/ valga, ni haga fee en juicio/ ni fuera de el, y solo queremos/ que se observe, guarde y cumpla/ por nuestra última y postrimera// voluntad este testamento, que/ ahora hacemos en la forma, que/ va prevenido, y lo que contuviere/ el papel, o memoria citada que/ se manifestara por el confidente/ que la presentare, dándosele a/ uno, y otro la entera validación/ y firma, que hubiere lugar por/ derecho: y en testimonio de ello/ así lo otorgamos ante el pre/sente Escribano público y tes/tigos, estando en nuestro Pala/cio Arzobispal desta ciudad de/ Sevilla en diez y ocho dias de el/ mes de octubre de mil setecien/tos sesenta y seis años: y el Excelentísimo/ y Eminentísimo Señor Cardenal Arzobispo/ Otorgante a quien yo el ynfras / cripto Escribano público doy fee/ conozco lo firmó su Eminencia/ en este rexistro, siendo presentes/ por testigos Don Francisco Saceda/ del Castillo Canónigo de la Ygle/sia Colegial de Nuestro Señor/ San Salvador, Don Phelix López/ de Argul Presbitero Mayordomo/ de Hacienda de su Eminencia,/ y Don Pío García Tagle Presbí/tero director de la mesa de la/ Dignidad Arzobispal= El Car/ denal de Solís Arzobispo de Se/villa= Phelix López de Argul=/ Francisco Saceda del Castillo= / Pío García Table= Pedro Leal / / Escribano público de Sevilla./

Esta copia yo Luis León Perez Es/cribano del Rey Nuestro Señor publico/ del número de esta ciudad, hizesa/car y saqué de un libro de rexistro/ de Escrituras que parece pasaron/ ante Pedro Leal Escribano pú/blico de dicho número, en cuyo oficio/ y papeles e succedido, y corregida/ con su original con quien concuer/da, la entregue a pedimento de la presente/ del Excelentísimo Señor Duque de Montellano, en/ 
Sevilla a diez y seis de agosto del/ año de mil setecientos ochenta y/ seis $=$ Enm.do $=$ contra $=\mathrm{v} \cdot \mathrm{e}=/$

[Rúbricas]

Yo Luis León Pérez Escrivano Público de Sevilla lo fize escribir e fize (...)./

\section{[Rúbricas]}

Los escrivanos públicos del número de esta ciudad de// Sevilla que aquí firmamos damos fee que Luis León/ Pérez de quien el documento antecedente parece firmado,/ y signado, es escrivano público de dicho número, fiel y legal/ y a sus escrituras, y demás que ante el susodicho han pa/sado y pasan se les da fee y crédito en todos Juicios y Tri/ bunales, y para que conste damos la presente en Sevilla,/ a diez y seis de Agosto del año de mill setecientos ochenta/ y seis=/

Antonio Madariaga Escrivano Público [Rúbrica], Luis de Palacios [y] Antonio Domínguez Escrivanos públicos de Sevilla [Rúbricas].

\section{FUENTES MANUSCRITAS}

\section{- Archivo de la Catedral de Sevilla}

Autos Capitulares de los años 1775-1776,Fondo Capitular, Sección Primera Secretaria, Signatura 07187.

Autos Capitulares del año 1786, Fondo Capitular, Sección Primera Secretaria, Libro 149, Signatura 07197.

\section{- Archivo Histórico de Protocolos Notariales de Sevilla}

Testamento del Cardenal don Francisco de Solis Folch de Cardona (1766), Sección Protocolos Notariales, Oficio 19, Legajo 13.149.

\section{- Archivo Histórico Nacional}

Copia del Testamento de don Francisco de Solís Folch de Cardona (1786), Sección Nobleza, Fondo Archivo de los Duques de Fernán Núñez, Signatura ES. 45168.NAHN/3, Legajo 915/1. 


\section{FUENTES DOCUMENTALES Y BIBLIOGRÁFICAS}

- ALONSO MORGADO José, Prelados sevillanos ó Episcopologio de la Santa Iglesia Metropolitana Patriarcal de Sevilla con noticias biográficas de los señores obispos auxiliares y otros relacionados con esta Santa Iglesia que escribió por disposición del Emmo. y Rumo. Sr. Cardenal Arzobispo Dr. D. Benito Sanz y Forés, Sevilla: Lib. e Imp. de Izquierdo y Compañia, 1906.

- ÁlVAREZ Y BAENA José Antonio, Hijos de Madrid, ilustres en santidad, dignidades, armas, ciencia y artes. Diccionario histórico por orden alfabético de sus nombres, que consagra el Illmo. y nobilisimo ayuntamiento de la imperial y coronada villa de Madrid, Madrid, B. Cano, 1789-1791

- CHILlÓN RAPOSO David, Patrocinio y mecenazgo del arzobispo don Jaime de Palafox y Cardona, Universidad de Sevilla, Sevilla, 2016 (tesis doctoral inédita).

- GARCÍA BERNAL Jaime, El ritual funerario de los arzobispos de Sevilla según los cuadernos manuscritos de los maestros de ceremonias de la catedral hispalense (siglos XVII-XVIII), en "e-Spania, Revista Electrónica" 17 (2014).

- MATUTE Y GAVIRIA Justino, Anales eclesiásticos y seculares de la muy noble y muy leal ciudad de Sevilla... que contienen las más principales memorias desde el año de 1701... hasta el de 1800, volumen II, Sevilla, 1887.

- LADERO FERNÁNDEZ Carlos L, La buena muerte de los arzobispos de Sevilla en el Setecientos, en "Tiempos Modernos: Revista electrónica de Historia Moderna"30 (2015) 1-27.

- LADERO FERNÁNDEZ Carlos L. y MARTÍN RIEGO Manuel, Arzobispos y caridad en la Iglesia de Sevilla (1755-1799), en "Anuario de Historia de la Iglesia Andaluza"7 (2014) 43-96.

- MARTÍn RIEGO Manuel, Sevilla de Las Luces, en ROS Carlos, "Historia de la Iglesia de Sevilla", (1992) 517-610.

- MORALES MARTÍNEZ Alfredo J. y VALDIVIESO GONZÁLEZ Enrique, Sevilla oculta: monasterios y conventos de clausura, Sevilla, 1987. 
- PORRES BENAVIDES Jesús, Un original desconocido (o perdido) y tres versiones del retrato del cardenal Solis, en "Archivo Español de Arte", volumen 81, 323 (2008) 315-322.

- VÁZQUEZ SOTO José María, Don Francisco de Solis Folch de Cardona, el noveno cardenal del título de los Doce Apóstoles, en "ABC Sevilla" 1 (4/01/1984) 63 